\title{
La poética disidente de Abigael Bohórquez
}

\author{
Juan Rogelio Rosado Marrero*
}

\section{Resumen:}

Hablar de la poesía de Abigael Bohórquez es hablar de una obra centrada en la lucha política contra el discurso "heteronormativo", el cual ha sido impuesto por las acciones "biopolíticas" que han llevado a cabo las distintas instituciones gubernamentales. Esta constante regulación sexual que se le hace al sujeto es lo que provoca el rechazo colectivo a todas esas prácticas erótico-afectivas que se alejan de la "norma" establecida. Por consiguiente, este trabajo examina la manera en la cual Abigael Bohórquez va constituyendo un sujeto lírico que cuestiona la visión "heteronormativa", así como los procesos de "normativización" que se le han realizado a los sectores homosexuales; logrando así una "visibilización" tanto de las prácticas sexuales alternativas (en este caso, las relaciones homosexuales) como de los propios sujetos disidentes que han sido marginados a las periferias de las esferas políticas y sociales. Para ello, nos centraremos en los poemarios Digo lo que amo (1976) y Poesida (1996), debido a que estos nos permiten develar tanto las acciones políticas realizadas por Abigael Bohórquez como el discurso disidente que fue construyendo a lo largo de su obra poética. De tal forma que partiremos de un análisis textual a una contextualización de los poemarios mismos con el fin de presentar ese cambio de paradigma que se da en su producción literaria: de una poesía homoerótica confesional (centrada más que nada en la descripción personal de la vida de los sujetos líricos) a una poesía de testimonio homosexual (cuyo principal objetivo es la denuncia política de los sectores marginales).

\footnotetext{
* Benemérita Universidad Autónoma de Puebla.
} 
Palabras clave:

Abigael Bohórquez, poesía de la disidencia, Digo lo que amo, Poesida. biopolítica, patologización de los sujetos.

\section{Abigael Bohórquez: el poeta de la disidencia política}

Entre el 26 y 27 de noviembre de 1995 fallece en Hermosillo, Sonora, uno de los poetas más sobresalientes de la literatura mexicana: Abigael Bohórquez. Su trágica muerte ocurrida en su pequeña vivienda de apenas un cuarto ha sido el principal motivo de consternación: ¿quién fue Abigael Bohórquez? ¿Cuáles fueron las razones de su aparente olvido dentro del canon poético mexicano? Sin duda alguna, las causas principales de su destierro literario yacen visibles dentro de su producción poética. Abigael Bohórquez no solo fue un poeta que vivió a contracorriente de los discursos hegemónicos, sino que también fue el principal artífice de una voz de disidencia política y cultural. En varios de sus poemarios, el escritor sonorense va desarrollando una poética de homosexualidad alternativa, que se contrapone al discurso institucionalizado por los organismos gubernamentales. De tal forma que cada uno de sus poemarios actúan como piezas fundamentales para ir reconstruyendo a un sujeto lírico que no solo desarticula el universo heterosexual, sino que además rompe con las prácticas sexuales alternativas que ya han sido "normativizadas" por el sistema capitalista. Por tanto, este trabajo tiene como objetivo mostrar la manera en la cual Bohórquez, a través de sus poemarios Digo lo que amo (1976) y Poesida (1996), subvierte el discurso hegemónico patriarcal con la finalidad de ir constituyendo a un sujeto lírico, capaz de trasgredir el universo "heteronormativo" de las prácticas sexuales. Para ello, nos centraremos tanto en el concepto de "biopolítica" planteado por Michel Foucault como en los procesos de "patologización" de los sujetos analizados por Judith Butler. 


\section{Digo lo que amo o la regulación sexual de los sujetos}

A pesar de la gran recepción que tuvo su poemario Memoria en la Alta Milpa (1975), el cual llegó a ser finalista del Premio de Poesía Aguascalientes de ese mismo año, no fue sino hasta la conformación de Digo lo que amo (1976) cuando Bohórquez tomó por primera vez las riendas de una poesía política cargado con un discurso de rebeldía homosexual. Aquí ya no estamos ante una voz poética que describe únicamente su sentir amoroso ${ }^{1}$; por el contrario, en este poemario vemos a un sujeto lírico que ya no le interesa declararse abiertamente homosexual, sino que más bien su intención es la de expresar su sexualidad y forma de pensamiento. Esa es la razón por la cual Bohórquez rompe con la estructura poética de sus primeros poemarios al presentarnos como poema inicial un rito de descubrimiento sexual entre la voz lírica y su acompañante masculino:

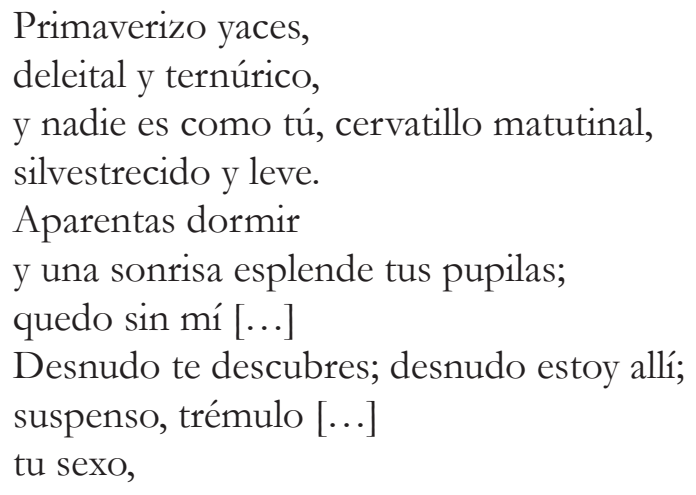

${ }^{1}$ Un ejemplo claro de ese tipo de poesía homoerótica es el poemario Memoria en la Alta Milpa. En sus páginas la voz poética contempla absorto la zona de Milpa Alta a modo de revelación sexual. Una revelación que es tanto para él como para el ser amado: "Esto es Milpa Alta, amor: colmena ardida,/ comarca del geranio y su techumbre;/ esto es Milpa Alta, amor, adormecida/ en la paz de su propia dulcedumbre" (Memoria 315). Por supuesto, la visión del poeta enamorado de su amante es lo que conduce gran parte del poemario. Es decir, en Memoria en la Alta Milpa percibimos a una voz poética que busca confesarle al lector su preferencia sexual. 
húmedo, cálidamente eléctrico, madero victorioso, con el recuerdo herido todavía

de la primera masturbación y el receloso orgasmo [...] (Digo 331).

Como vemos, es la voz poética la que comienza el juego ritualizador con el joven inexperto. El cuerpo desnudo del amante es descrito a partir de un lenguaje al estilo pastoril, en donde cada palabra convierte al iniciado en un ser bello e inocente; desatando así una mirada perversa tanto del oficiante como del propio lector que actúa como una especie de asistente-voyeur. Sin embargo, esa propia utilización del lenguaje pastoril no solo queda en un plano metafórico para el poema, sino que trasciende al espacio mismo de la disidencia política: el hecho de que Bohórquez se apropie de un lenguaje tan institucionalizado dentro del contexto literario para construir su escena homoerótica, habla de una preocupación sobre la misma significancia de la palabra. Es decir, Bohórquez retoma este lenguaje pastoril con la clara intención de subvertirlo para que el lector se dé cuenta de la carga simbólica que yace dentro de las palabras mismas; aspecto que fue desarrollando a lo largo del poemario. No por nada, Bohórquez nos presenta el poemínino "Echufate" como una clara muestra de esa subversión discursiva, al transfigurar el canto dulce de un pajarito en una referencia puramente sexual (la masturbación): "Pajarito atrapado/ entre las trompas/ de falo/ pío/ pío/ pío” (Digo 339). En consecuencia, podemos afirmar que dicho poema iniciático ("Primera ceremonia") es el parteaguas para el desarrollo de una poética que busca la desestabilización de un determinado grupo de lectores, en este caso los homofóbicos.

No obstante, así como Bohórquez constituye todo un juego metafórico para la recreación de determinadas escenas sexuales, en otros momentos la propia voz lírica se desentiende de ese método de construcción lingüística y en su lugar prefiere utilizar un lenguaje sexual más directo y sin tabúes: "Dejadlo al villano pene/ yendo y viniendo;/ una vez entando/ y otra vez saliendo/ por sécula su culorum;/ que pene/ qué pene!!!” (Digo 342). A pesar de la disonancia que pueda causar esa mezcla de procedimientos lingǘsticos, 
la finalidad comunicativa de cada uno de los poemas termina por ser la misma: presentarnos el universo censurado de las prácticas homosexuales. Debemos recordar que cuando Bohórquez escribe su poemario está vigente el tabú de los homosexuales, a los cuales se les considera como los sectores "anormales" o los "desviados" de las prácticas heterosexuales impuestas por la colectividad ${ }^{2}$. Bohórquez es muy consciente de ello; a tal punto que en muchos de los poemas aparece retratada esa "biopolítica" que vigila y castiga a todos los seres que se salen de la norma establecida. Por ejemplo, en "Indulto" el poeta sonorense denuncia a una sociedad civil cuyo principal objetivo es el juzgamiento homofóbico: "Ustedes,/ vosotros,/ jueces y detectores,/ infamiliares de circuito cerrado/ y huevecitos de transistores [...]" (Digo 357). De igual forma, en varios de sus escritos recurre también al lenguaje oficial de los textos evangélicos con la idea de constituir un reclamo en contra del sistema normativo que rige a esa sociedad conformada por religiosos homofóbicos, que a partir de una ideología moralista realizan un sometimiento social hacia los grupos "anormales":

Es preciso volvernos a tiempo hacia los que no nos ignoran: ser prudentes, pacientes, cristianamente alcohólicos, acostólicos y remonos. Los enemigos no tienen conducta ni sentido;

${ }^{2}$ En cuanto a esto, Michel Foucault señala que la crisis de las identidades sexuales comienza a resonar dentro del orbe institucional a partir del triunfo de la psicología como la ciencia encargada de tratar y categorizar las diversas enfermedades mentales, sobre todo las desviaciones sexuales. En ese sentido, hacer de la psicología una arma del Estado es lo que permite el nacimiento de una "biopolítica", que no es otra que "un poder que se hizo cargo del cuerpo y de la vida o que, si lo prefieren, tomó a cargo la vida en general, con el polo del cuerpo y el polo de la población [...] El objetivo de la biopolitica es la vida y por lo tanto tener el derecho privilegiado de decidir sobre la vida y la muerte de los individuos." (Defender 217-218). Esta regularización de la vida biológica por parte del Estado es lo que inaugura, según Foucault, un sistema totalitario y racista (sexista). 
se hacen ver donde menos

se les quiera ver.

pero todo fue algo más:

yo acerqué mis labios a tu frente,

a tus mejillas redentoras,

a tus labios, no sé;

y la beata, el adúltero, el sacrílego,

el cura, el homicida, el drogadicto

la incestuosa y el sátiro,

el centurión,

la distinguida cogelona,

la sociedad de padres de familia

y adoradores del santísimo,

los fetógrafos,

los puros elegidos,

no sé qué hacían

emboscados,

allí,

en el monte de los olivos (Digo 334)

Esta misma situación vuelve a estar presente en el poema "Levítico 20: 13", en donde el discurso judaico acerca de la abominación y la permitida ejecución de los homosexuales es subvertida con la finalidad de retratar los encuentros homoeróticos de la voz poética: "Ay! Levítico... / tú y yo; que en un dos por tre/ sé tú,/ hombre con hombre,/ tú y yo,/ tendremo ayuntamiento con dolore,/ yo,/ y en esa esquina, yo y tú [...]" (Digo 345). Más que reclamarle a una determinada institución religiosa, Bohórquez transgrede los textos bíblicos con la idea de mostrar a un Estado normativo que, paradójicamente, carece de una verdadera conciencia moral. En vez de regular las prácticas delictivas de mayor injerencia religiosa y estatal (el adulterio, el asesinato, el incesto, la drogadicción), esta "biopolítica" prefiere sancionar los desvíos sexuales como la homosexualidad; demostrando con ello lo referido por Foucault: "el campo de la anomalía está íntimamente connotado por al menos algunos elementos concernientes a la sexualidad" (Los anormales 159). En otras 
palabras, lo más perseguido por la normatividad son los seres que trasgreden la sexualidad institucionalizada: la sexualidad (y más bien la homosexualidad) se convierte en un tabú dentro del discurso político, social y religioso. Solamente la confesión ante la autoridad (ya sea un sacerdote o un psicólogo) pasa a ser el único medio legítimo por el cual el tabú puede salir a la luz. Por consiguiente, Digo lo que amo se aleja de esa literatura homosexual que hace de la confesión una supuesta práctica subversiva; debido a que dicho acto confesional del yo hacia el lector termina por encerrar al discurso homosexual dentro de una visión claramente heterosexual: es el propio lector el que, influenciado por ciertos prejuicios socialmente instituidos, actúa como juez y verdugo. En ese sentido, el poemario de Bohórquez se presenta como un discurso literario de disidencia política, ya que en vez de confesarse la voz poética pone de manifiesto su "ser-homosexual". Y esto lo podemos ver constatado desde los mismos epígrafes elegidos por Bohórquez como antesala del poemario; siendo el proceso judicial de Oscar Wilde el que más reminiscencia tiene dentro del texto:

Digo lo que amo es un homenaje a Oscar Wilde con motivo del 75 aniversario de su muerte, pero sobre todo por la afrenta que sufrió cuando fue condenado a dos años de trabajos forzados (1895-1897), en la Inglaterra victoriana, acusado de seducción y sodomía [...] A través de veinte poemas, el autor resemantiza el vocabulario jurídico que reprime, censura y juzga las prácticas afectivas y sexuales no autorizadas [...] Digo lo que amo es la declaración de libertad del yo poético a veces desafiante, otras eróticas, pero también enternecido en un mundo en el que las ideas heteronormativas de la sexualidad binaria permean las conciencias de los moralistas; por eso, el poeta arremete en contra de esos juicios, prepara su defensa a través de la poesía, expone la naturaleza humana, el deseo y la realización como formas de libertad; reduce la burla, e incluso, plantea la performatividad de las identidades sexuales al desenmascarar la impostación de una masculinidad [...] (Bustamante, "Abigael Bohórquez" 22-23). 
Ahora bien, de los veinte poemas que conforman Digo lo que amo existe uno en particular en donde Bohórquez va desarrollando una forma de pensamiento que se aleja del propio colectivo homosexual. En "Trilogía policiaca" el escritor sonorense da muestras de un verdadero posicionamiento de izquierda radical, ya que en los múltiples versos somos testigos de una lucha política entre la voz lírica y las fuerzas coercitivas de la ley, cuyo principal objetivo es el exterminio de los grupos revolucionarios disidentes, representados en el poema por la imagen de los estudiantes:

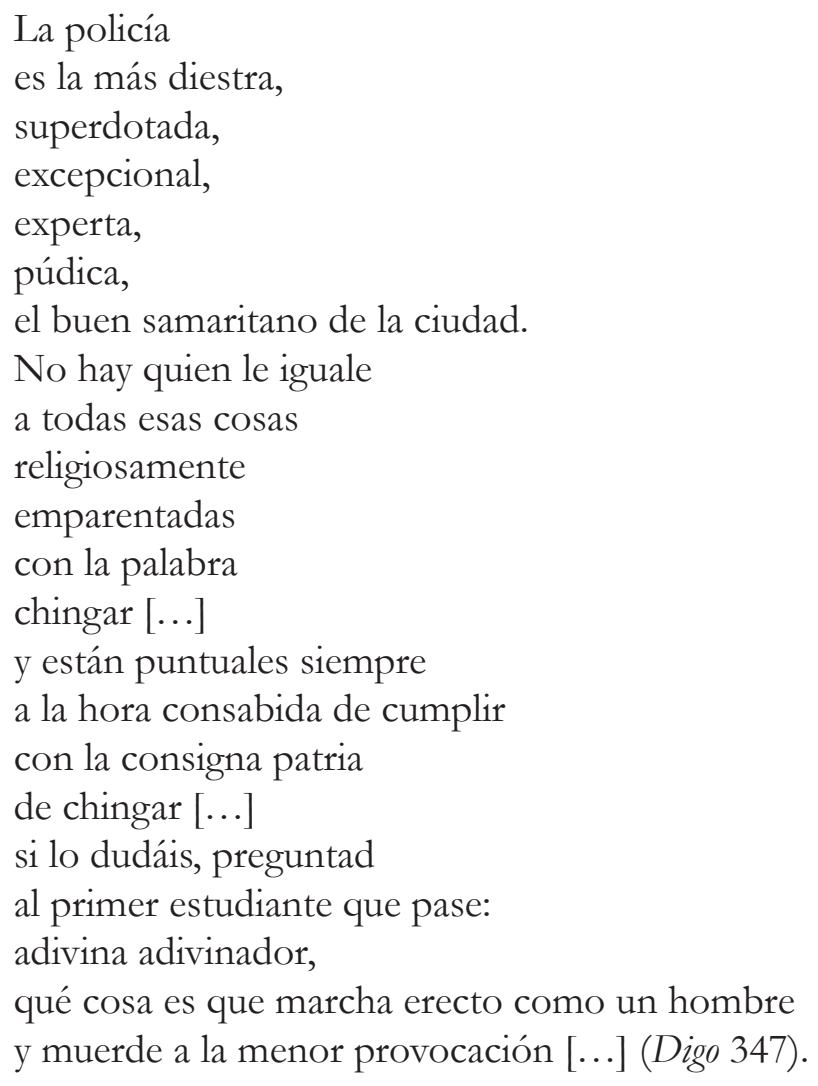

Es precisamente en este poema cuando Bohórquez se pone al mismo nivel que los estudiantes universitarios, en un intento por precisar que antes de defender la propia homosexualidad primero hay que luchar por el pensamiento político de izquierda. Esa es la 
gran diferencia que el poeta sonorense entabla con las otras publicaciones de carácter homosexual: ante todo, Bohórquez se presenta a sí mismo como una voz de rebeldía absoluta, incluso para el propio sector homosexual; debido a que él mismo preveía la fuerte crisis que tendrían los movimientos homosexuales de su época. Para los años setenta, y sobre todo los ochenta, empezó una fuerte proliferación del llamado "mercado capitalista gay". Los movimientos homosexuales que luchaban por lograr una "visibilización" dentro de la sociedad que los despreciaba terminaron por ser absorbidos por el gran monstruo del capitalismo, propiciando con ello una crisis de identidad para los propios miembros del grupo. El gay, debido a sus múltiples triunfos, pasó a ser un objeto de intereses para el sistema económico institucionalizado. El mercado capitalista, al darse cuenta de la gran demanda económica que significaba el movimiento, decidió apoyarlo y hacerlos "visibles" para la sociedad en general. Los homosexuales pasaron a ser una especie de cultura específica, la nueva burguesía gay, cuyos miembros estaban conformados, en su inmensa mayoría, por varones blancos de clase media o alta con profesiones liberales o trabajos estables (Sáez 30). En ese sentido, como bien señala Leo Bersani, los tan afamados triunfos de los movimientos gays en realidad fueron meras victorias, otorgadas casi siempre por los grupos privilegiados del capitalismo económico (29). De tal forma que la lucha por "hacerse visible" ha degenerado en una suerte de cultura "normativizada", que se ha vuelto tan excluyente como alguna vez la sociedad lo fue con él:

El movimiento de liberación homosexual se ha reducido a conciencia de contradicción. La vida gay ha producido sus propios regímenes disciplinarios, sus propias técnicas de normalización, bajo la forma de corte de pelos obligatorios, camisetas, dietas, el uso de piercing por todo el cuerpo y el constante ejercicio físico (Halperin 52) ${ }^{3}$.

${ }^{3}$ Para Óscar Guasch, los movimientos de liberación homosexual se han transformado en una cultura muy específica y reconocible para el medio mundial 
En el caso particular de México la situación fue casi similar. Incitados por la apertura política-económica de los movimientos homosexuales en varias partes del mundo, el grupo de LG mexicano manifestó sus actividades de liberación a través de múltiples marchas y discursos. No por nada, los años que comprendieron el período de 1978 a 1984 fueron vislumbrados como la "era dorada del movimiento de liberación homosexual mexicano". Y significativamente fue en esa misma etapa cuando el mercado editorial decidió abrir sus puertas a uno de los íconos más grandes de la literatura mexicana escrita por homosexuales: El vampiro de la colonia Roma. La novela de Luis Zapara, publicada en 1979, dejó muy en claro que existía un amplio mercado de lectores homosexuales latinoamericanos, que hasta esos momentos todavía no tenía cabida dentro del imaginario de las casas editoriales. Para Rodrigo Laguarda el triunfo de la novela El vampiro de la colonia Roma fue el parteaguas para el desarrollo y la sustentación de la literatura gay en México:

En 1979 fue publicada la novela de Luis Zapata, El vampiro de la colonia Roma, cuya primera edición constaba de diez mil ejemplares. Este libro se convirtió en un verdadero éxito editorial. Fue la primera novela reconocida como gay en lograr la atención del público mexicano. La crítica la convirtió en un clásico de la literatura homosexual mexicana contemporánea. Fue traducida al inglés como Adonis García: A Picaresque Novel. El crítico literario David William Foster ha dicho que esta fue la primera novela latinoamericana, específicamente gay, en aparecer en inglés (125).

(la nueva burguesía gay retratada por Sáez): "Por un lado, la progresiva normalización de la realidad gay implica su institucionalización: el Estado pasa a regular la afectividad gay a través de medidas legislativas (las leyes de parejas de hecho equiparan la afectividad gay con la afectividad heterosexual). Por otra parte, la sociedad global se vuelve gay al reproducir la mayoría de rasgos que hasta el momento solo se hallaban presentes en esa subcultura (y entre ciertas élites, intelectuales y artistas)" (91-92). 
Sin embargo, la aparición de la novela de Zapata trajo consigo otro problema de mayor injerencia para muchos de los miembros de los grupos homosexuales alternativos, como fue el caso del propio Bohórquez: ¿hasta qué punto se podía decir que ese triunfo de las letras homosexuales fue en realidad una proclama de voz política comprometida con una causa específica? La respuesta es evidente: si bien la novela de Zapata inauguró la literatura homosexual en México, también es cierto afirmar que esa gloria no fue para todos los grupos homosexuales. El triunfo del movimiento gay por "hacerse visible" acabó por excluir y acallar a otras voces que estaban en contra de esa "normativización" impuesta por el sistema económico capitalista. De allí que Bohórquez, al notar los tintes que estaba teniendo el movimiento de liberación homosexual, optó por conformar una poética homosexual de disidencia con el fin de "politizar" aún más la propia sexualidad: hacer del pensamiento homosexual un posicionamiento político. Por consiguiente, cuando Bohórquez en "Trilogía policiaca" se pone al mismo nivel que los estudiantes universitarios, lo que está privilegiando es la denuncia política más que la denuncia homosexual. Y fue este pensamiento político lo que generó su completa censura dentro del campo de las letras mexicanas: "la disidencia política de Abigael Bohórquez le hizo pasar por las vicisitudes de su carrera literaria, además de las económicas” (Bustamante, “Juan Bañuelos” 103).

${ }^{4}$ La defensa fervientemente de su posicionamiento político fue lo que causó muchos de sus conflictos personales con varios de los principales gestores de la cultura en México. Estas afrentas personales acabaron por arrojar a Bohórquez a la zona más marginal posible: fue censurado de todas las antologías y su nombre pasó a convertirse en un mito; a pesar de que en 1993 ganó el Premio de Poesía Clemencia Isaura por su poemario Navegación en Yoremito (Églogas y canciones del otro amor). 


\section{La "patologización" de los cuerpos disidentes: el caso de Poesida}

A pesar de la censura que empezó a sufrir su obra poética, Bohórquez nunca dejó de lado su pensamiento político. Prueba de ello es uno de sus últimos poemarios, Poesida (1996), en donde ya desde el prólogo mismo el autor busca rescatar el testimonio íntimo de todo ese grupo de homosexuales que se han visto afectados por la enfermedad; lo que les ha valido no solo una estigmatización social por parte de los sujetos "normativizados", sino además una "deshumanización” de sus cuerpos vía una "patologización” institucionalizada (el proceso de "invisibilización" del sujeto) ${ }^{5}$ :

Cuánta gente pública y privada desapareció muerta de arcangelismos, de ninfomanía, del susto, porque el Sida era la muerte que no se atrevía a decir su nombre; cuánta gente pública y privada se fue poniendo flaquita, sin pelos y se murió de dulce muerte primaveral; de fiebre de heno, porque se le fue la tripa, de sida nunca, lo que diría el Comendador.

Traigo este documento cruel pero solidario para pedir comprensión infinita para los ciudadanos del mundo que han muerto víctima de este cáncer finisecular y bondad para estos poemas del paraíso perdido que algún día que mi imagina-

${ }^{5}$ Tomamos el concepto de "patologización" de los planteamientos clínicos propuestos por Judith Butler. En Deshacer el género Butler afirma la existencia de toda una maquinaria clínica que se encarga no solo de mirar el estado físico y psicológico de los sujetos, sino también de constituir un discurso institucional (el médico) que certifique la separación social entre los cuerpos "sanos" y los cuerpos "enfermos". De ahí que Butler denomine a esos métodos de diagnosticación "únicos" como los procesos de "patologización del sujeto", cuyos efectos producen una violencia simbólica sobre los cuerpos diagnosticados (18). En ese sentido, la "patologización" actúa sobre todos aquellos sujetos que, de alguna u otra manera, desestabilizan la "normatividad" institucionalizada, como es el caso de las desviaciones sexuales, las filias, los trastornos psicológicos y las adicciones. 
ción no alcanza a predecir reencontraremos: Poesida, poesía testimonial de quien pudo escribirla con todas las palabras de que es capaz un hombre, en Hermosillo, Sonora, a los veinte días del mes de marzo de mil novecientos noventa y uno (Poesida 543).

En Poesida Bohórquez constituye un ataque directo a todos esos grupos que han hecho de la homosexualidad un estado "normativizado". De ahí que el poemario elija como portavoz a un sujeto homosexual doliente y enfermo, que sufre el rechazo de esos sectores que lo han "patologizado" como una "verdadera amenaza social". Bajo esta perspectiva, el logro principal del poemario se centra en esa "visibilización" que se le da a los grupos de homosexuales enfermos de Sida, que han sido relegados (incluso por los propios homosexuales) a las periferias marginales. No por nada, uno de los poemas más reveladores que tiene el texto es justamente "Retratos", en donde la voz lírica expone diez cuadros de vida de personas que han sido contagiadas por esa enfermedad terminal. El caso más interesante es el de la "Pájara Gustavo", que siendo un excelente maestro termina por ser destituido debido a su estado clínico, muriendo así en la soledad y miseria absoluta:

\section{Este era Pájara Gustavo}

Fue profesor de educación primaria

y tuvo el alma de cristal (soplado),

por eso lo corrieron de trabajar;

hizo versitos, coronas para muertos, valses para quinceaños;

rezaba novenarios,

hablaba solo con la Virgen María, se le apareció El Diablo,

y una mañana

lo descubrieron tieso, con el alma trizada, en libertad de alcohol y de tabaco, amoratada pájara tucana, alma de Dios, 
salvada de sin amor, de sin calor humano. Ni divino (Poesida 566).

Con este cuadro de vida, Bohórquez volvió a poner sobre la mesa la importancia de constituir una voz política de disidencia homosexual, ya que para el poeta sonorense la situación del sida no se quedó únicamente en el plano clínico, sino que trascendió a las propias esferas de la sociedad. El sida, por tanto, se transformó en el principal mecanismo para el accionar "patológico" del Estado: por un lado, los países afectados se adueñaron de los procesos de "diagnosticación" de los sujetos (ya sea haciendo propagandas televisivas explicando las consecuencias de la enfermedad o patrocinando campañas médicas de regulación constante); por el otro, el Estado también intervino en la creación de una estigmatización colectiva contra todos aquellos homosexuales que se habían salido de la "norma" establecida (los enfermos de sida), al presentar como imagen icónica de la enfermedad a un sujeto que se ha "infectado" debido a sus prácticas sexuales inadecuadas y que además pertenece, por esas mismas razones, a una clase social baja ${ }^{6}$. Para Bohórquez, este despertar del poder "biopolítico" del Estado contra los homosexuales enfermos de Sida significó una nueva afrenta social y poética. En su introducción a Poesida el poeta sonorense señala que esta "patologización" hecha al cuerpo enfermo, aunado a la situación económica y racial, es lo que ha "silenciado" el trabajo artístico de los homosexuales de izquierda. Bohórquez es muy claro al decir que la enfermedad del sida fue el parteaguas para la separación radical entre los distintos grupos de homosexuales (los "aceptados" por el sistema y los "rechazados" por la colectividad):

${ }^{6}$ A partir de esa separación económica y social, los grupos homosexuales devienen en una pugna constante entre ellos mismos, cuyos principales catalizadores son "la nueva burguesía gay", apoyada por el sistema capitalista debido a su enorme adquisición económica, y los grupos de homosexuales disidentes, como es el caso de Bohórquez, cuyo nivel de adquisición era casi nulo. Esa es la razón por la cual muchos de los grupos de homosexuales disidentes se encontraban marginados a espacios altamente periféricos (Guasch 69). 
Dentro de la otra violencia cotidiana cuya espectacularidad sanguinaria se asume eficazmente sin escándalo hipócrita contra los homosexuales aun ahora todavía, hizo su aparición el Sida, y como el ciudadano que elige encantadoramente entre la solidaridad o el crimen y que necesita proezas quiere maniobras y reductos para justificar su moralina del yo nunca, me salo, y por aquello que de siempre pretenderán tapar el sol con un pulgar [...] señaló bíblicamente de nuevo a los homosexuales como apestados del siglo, satanizando su inclinación amorosa con las cruces del kukuxclanes, y los homosexuales atónitos y zarandeados hacia las cámaras de gases de los más acreditados conjuros malignos y los tentáculos del abismal horror del desempleo, separados de sus salarios, descaradamente exorcizados por la prensa y los pastores de la iglesia, porque era castigo de Dios (Poesida 543).

Como hemos dicho anteriormente, Bohórquez busca retratar en su poemario una visión más humana sobre la enfermedad y, por consiguiente, de los propios homosexuales afectados por ella. $\mathrm{Y}$ este aspecto resulta ser trascendental para el poemario, ya que en sus páginas el sida no aparece como una simple enfermedad que afecta al cuerpo, sino que su participación sobre los personajes permite el desarrollo de un sentimiento de empatía lectora. En vez de reclamar directamente a los seres divinizados, la voz lírica se cuestiona a sí misma sobre la situación precaria de su nueva vida adquirida; logrando con ello un momento de revelación poética que se contrasta con la imagen reluciente del sol brillante y los niños inocentes jugando en la playa:

Y de repente, el Sida.

¿Por qué este mal de muerte en esta playa vieja

ya de sí moridero y desamores, en esta costra antigua

a diario levantada y revivida, en esta pobre hombruna de suyo empobrecida y extenuada 
por la raza baldía? Sida.

Qué palabra tan honda

que encoge el corazón

y nos lo aprieta.

Afuera, al sol, juguetean los niños,

agrio viento,

con un barco menudo

en mar revuelto (Poesida 549).

Al representarse también como un miembro más de la comunidad enferma, la voz poética va construyendo con el lector un espacio íntimo de resistencia, en donde la denuncia política se va entremezclando con el proceso de "patologización" de los personajes: el hecho de transcribir textualmente la palabra "Sida" es una forma de afrontar a ese sistema institucional que ha hecho de las palabras una carga simbólica de manipulación patriarcal; es decir, el lenguaje no solo es masculino, sino que además es altamente "heteronormativo". De ahí que Bohórquez exprese con ironía que morir de sida es "morir de forma diferente" (Poesida 553). Sin embargo, esta diferenciación que pareciera ser discriminadora (el hecho de que un homosexual enfermo de sida es un sujeto "diferente" al resto de los homosexuales "sanos"), al final termina por ser el elemento discursivo que resignifica a la propia enfermedad: en los poemas de Bohórquez, el enfermo de sida no es una persona a la cual le debemos tener repulsión y lástima, por el contrario, el poemario en sí permite la restitución de ese grupo disidente como la voz misma de esa lucha política contra el sistema "heteronormativo" impuesto. En consecuencia, se da una "despatologización" de la enfermedad, ya que su accionar dentro del poemario no es de corte clínico sino más bien es de tipo político; situación que se deja entrever cuando Bohórquez subvierte el pensamiento poético de Walt Whitman: “¿me celebro a mí mismo y me canto a mí mismo?” (Poesida 553). Aquí ya no se le canta ni a la naturaleza ni a la vida plena, aquí se le canta a los cuerpos enfermos, a los sujetos contagiados por el Sida. Inclusive, esta subversión que se le hace al pensamiento de Whitman actúa también como esa toma de consciencia por parte de la 
voz lírica: al cantarle a los sujetos enfermos, Bohórquez transgrede el universo sagrado protegido por el poeta endiosado ${ }^{7}$. A diferencia del poeta estadounidenses, Bohórquez entiende que Dios le ha dado la espalda y lo ha dejado tirado en una fosa común, rodeado de cuerpos enfermos y olvidados. Por tal motivo, el poeta sonorense no solo cuestiona el posicionamiento central de la poética de Whitman, sino que además deja de manifiesto su descontento con ese universo de lo sagrado que los poetas endiosados intentan comprender. Estas ideas se ven muy bien reflejadas en el poema "Duelo", en donde existe, como el título mismo lo indica, una ruptura espiritual entre el orbe de lo sagrado y los sujetos enfermos de Sida, representados por la propia voz lírica:

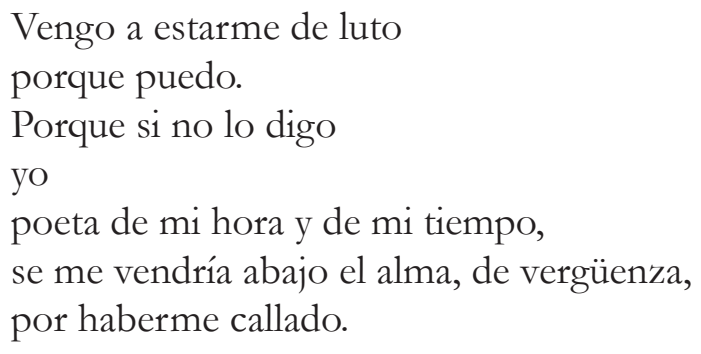

Qué natalicio nuevo de la ausencia, qué grave día, qué turbio sol apenitas ayer abeja de oro,

${ }^{7}$ En cuanto a esto, María de los Ángeles Castro Hidalgo afirma que existe en la poética de Whitman una conexión divina entre el cuerpo y el alma, en donde la trascendencia final del ser se logra a partir de la comunión espiritual con lo infinito, lo inmortal, lo divino: “[...] el objetivo whitmaniano es evolucionar conscientemente, constantemente hacia el infinito, hacia lo inmortal, Dios [...] Para Whitman, la vida puede ser convertida en un bello poema a través del accionar infatigable del alma [...] Es decir, inferimos nosotros, materia impregnada de infinito, de inmortalidad, conscientemente orientada hacia el bien, hacia Dios. El ser humano es y está rodeado de vida [...] Nos cuenta su gran biógrafo Allen que Whitman era ciertamente creyente. Según su juicio, la religión era un medio noble que permitía desarrollar lo bueno en el ser humano" (96 y 98). 
qué viento de crueldad este domingo,

qué pena.

Pero está bien;

en este mundo todo está bien:

el hambre, la sequía, las moscas,

el appartheid, la guerra santa, el Sida,

mientras no se nos toque a Él;

Ese no cuenta, simplemente está Allá, loco de risa, próspero de la muerte, agusto (Poesida 564-565).

Para Bohórquez, la poesía sí posee una verdadera esencia política y, por eso mismo, todo poema es en realidad una forma de denuncia social. En el caso de Poesida, la denuncia político-social fue tan evidente que, a pesar de haber ganado el concurso organizado por el CONASIDA, el poemario pasó a ser censurado por el propio organismo institucional:

Por su parte, Poesida es el texto que Bohórquez ya no pudo ver publicado. Libro ganador del Premio Internacional de Poesía, convocado por el CONASIDA, la Organización Panamericana de la Salud y la UNAM, en 1992, se publicó gracias al esfuerzo del poeta Mario Bohórquez y la editora Elizabeth Algrávez, quienes en octubre de 1995, en la ciudad de Tijuana, Baja California, recibieron el manuscrito por el autor. Bohórquez sometió su poemario al concurso debido a que su amiga Ysabel Gracida se lo sugirió; no obstante, las instituciones convocantes ni publicaron la obra ni le entregaron el monto económico. Poesida es un libro polémico porque con su publicación, los comentarios malintencionados refirieron que el autor hablaba sobre su condición serológica [...] Las instituciones convocantes del premio no supieron qué hacer con él; resultaba un testimonio muy fuerte para la mirada de los homofóbicos que no dimensionaron la importancia 
de este texto-testimonio. Bohórquez fue el primer poeta que llevó al espacio de la escritura el tema serológico (Bustamante, "Abigael Bohórquez" 31).

Si bien es cierto que Poesida puede ser considerado como un poemario testimonial, en donde la enfermedad es transportada del campo médico (ser una enfermedad que en realidad puede contagiarse por medio de la sangre) al espacio social (ser una enfermedad que castiga únicamente a los homosexuales por ser los "desviados" de la norma sexual), tampoco podemos dejar de lado la idea de que el poemario fue escrito con la finalidad de romper con la "patologización” que se ha hecho del sujeto homosexual. En ese sentido, el poemario apela a un reclamo colectivo contra los grupos "diagnosticadores" de la sexualidad (tanto las instituciones heterosexuales como los propios homosexuales "normativizados" por el capitalismo económico). Por ello, siguiendo esta consigna, Bohórquez se deshace del tema "homoerótico" que había venido construyendo en sus poemarios anteriores con la finalidad de adentrarse a un pensamiento cada vez más político y disidente (una poesía "homopolítica"), como es el caso de Poesida. Situación que puede notarse en el propio plano discursivo cuando la voz lírica deja de lado la temática confesional (muy utilizada por la literatura homosexual de esos años) en pos de una enunciación más al estilo testimonial.

\section{A modo de conclusión}

Tanto en Digo lo que amo como en Poesida se constituye una voz que no únicamente logra politizar las desviaciones sexuales vía la "visibilización" de las prácticas erótico-afectivas, sino que también consigue liberarse de esa "normativización" política y social que estaban teniendo los homosexuales en los años ochenta y noventa. De tal forma que en la poesía de Abigael Bohórquez encontramos un pensamiento político de resistencia contra todos aquellos campos que han sido consumidos por una "biopolítica" estatal (como son el caso de los servicios médicos y el mercado capitalista). Es 
decir, en la poesía de Bohórquez encontramos las pautas que han llevado a la "normativización" de un amplio sector de los homosexuales, los cuales a su vez han constituido, paradójicamente, todo un discurso identitario de lo que significa ser supuestamente "gay"; provocando así el desarrollo de una "biopolítica del sujeto":

Las formas modernas de gobernabilidad requieren que los ciudadanos sean libres, para que descarguen al Estado de algunas de sus funciones reguladoras, imponiéndose por su propia voluntad reglas de conducta y mecanismos de control [...] El Estado ya no necesita atemorizar o coaccionar a los sujetos para que tengan un comportamiento adecuado: puede, con toda seguridad, dejar que tomen sus propias decisiones en el marco de la sacrosanta esfera privada de la libertad personal en la que ahora habitan, porque dentro de esa esfera ellos controlan libre y espontáneamente su propia conducta y la de los demás (Halperin 36-37).

Tal y como lo subraya David Halperin, el Estado ha "normativizado" a un amplio sector homosexual al crearles un determinado estilo de vida y una forma carnavalesca de manifestación política, con el objetivo de "acallar" a los grupos de homosexuales disidentes que se niegan a ser absorbidos por el mercado capitalista. En ese sentido, tanto Digo lo que amo como Poesida terminan por ser un ataque directo a todo ese amplio sector homosexual, que busca la "normativización" de sus prácticas erótico-afectivas; de ahí la negación de Bohórquez por continuar con ese discurso homoerótico ya institucionalizado. Situación que le ha valido una censura casi total de su obra ${ }^{8}$. Por tanto, en ambos poemarios Bohórquez nos construye todo un discurso alternativo que permite la "despatolo-

${ }^{8}$ En un país en donde la literatura homosexual de mayor impacto editorial se centra más que nada en la temática homoerótica, la poesía disidente de Bohórquez sigue siendo ignorada, incluso dentro de la propia academia. Son muy pocos los lectores especializados que tratan de rescatar del anonimato una obra poética que incluso hoy en día puede ser considerada como altamente "desafiante". 
gización" del sujeto homosexual disidente. Al retratar dentro de sus poemas los sectores "biopolitizados", contraponiéndolos con la mirada testimonial del sujeto lírico, Bohórquez subvierte los discursos institucionales con la finalidad de ir "visibilizando" a esos grupos políticos disidentes que han sido marginados a las periferias de las esferas políticas y sociales. Bohórquez, por tanto, restituye en estos dos poemarios a un sujeto que se niega a ser visto desde una simple "patologización" de su cuerpo. Así, a través de esa negatividad del sujeto, Bohórquez hace un quiebre con la literatura homosexual de su tiempo, al privilegiar un discurso de lucha social en vez de una pragmática puramente amorosa; dando como resultado una obra poética que va mucho más allá de la simple "visibilización" de las distintas prácticas sexuales alternativas.

\section{Bibliografía}

Bersani, Leo. Homos, Manantial, 1998.

Bohórquez, Abigael. Poesía reunida e inédita, Instituto Sonorense de Cultura, 2016.

---. Memoria en la Alta Milpa. Bohórquez, pp. 291-324.

---. Digo lo que amo. Bohórquez, pp. 325-358.

---. Poesida. Bohórquez, pp. 541-574.

Bustamante Bermúdez, Gerardo. "Abigael Bohórquez, el poeta que clama en el desierto". Bohórquez, pp. 5-37.

---. "Juan Bañuelos y Abigael Bohórquez: la poesía como resistencia y representación social". Acta Poética, vol. 37, no. 2, 2016, pp. 87-115.

Butler, Judith. Deshacer el género. Paidós, 2006.

Castro Hidalgo, María de los Ángeles. "Walt Whitman: la experiencia humana y su dimensión poética". Revista de Filosofía de la Universidad de Costa Rica, vol. 33, no. 80, 1995, pp. 95-101.

Foucault, Michel. Hay que defender la sociedad. Akal, 2003.

---. Los anormales. Fondo de Cultura Económica, 2007.

Guasch, Óscar. La crisis de la heterosexualidad. Laertes, 2000. 
Halperin, David. San Foucault. Para una hagiografía gay. Ediciones literales, 2007.

Laguarda, Rodrigo. "De lo rarito al ambiente: aproximación a la construcción de la identidad gay en la Ciudad de México". Clío, Nueva época, vol. 5, no. 34, 2005, pp. 119-131.

Sáez, Javier. Teoría queer y psicoanálisis, Síntesis, 2004. 